\title{
Bond Characteristics of Macro Polypropylene Fiber in Cementitious Composites Containing Nanosilica and Styrene Butadiene Latex Polymer
}

\author{
Jae-Woong Han, ${ }^{1}$ Ji-Hong Jeon, ${ }^{2}$ and Chan-Gi Park ${ }^{3}$ \\ ${ }^{1}$ Department of Bio-Industry Mechanical Engineering, Kongju National University, Yesan 70-340, Republic of Korea \\ ${ }^{2}$ Department of Environmental Engineering, Andong National University, Andong 74-760, Republic of Korea \\ ${ }^{3}$ Department of Rural Construction Engineering, Kongju National University, Yesan 70-340, Republic of Korea \\ Correspondence should be addressed to Chan-Gi Park; cgpark@kongju.ac.kr
}

Received 16 April 2015; Revised 27 July 2015; Accepted 4 August 2015

Academic Editor: Osman Gencel

Copyright ( 2015 Jae-Woong Han et al. This is an open access article distributed under the Creative Commons Attribution License, which permits unrestricted use, distribution, and reproduction in any medium, provided the original work is properly cited.

\begin{abstract}
This study evaluated the bond properties of polypropylene (PP) fiber in plain cementitious composites (PCCs) and styrene butadiene latex polymer cementitious composites (LCCs) at different nanosilica contents. The bond tests were evaluated according to JCI SF-8, in which the contents of nanosilica in the cement were $0,2,4,6,8$, and $10 \mathrm{wt} \%$, based on cement weight. The addition of nanosilica significantly affected the bond properties between macro PP fiber and cementitious composites. For PCCs, the addition of $0-2 \mathrm{wt} \%$ nanosilica enhanced bond strength and interface toughness, whereas the addition of $4 \mathrm{wt} \%$ or more reduced bond strength and interface toughness. The bond strength and interfacial toughness of LCCs also increased with the addition of up to $6 \%$ nanosilica. The analysis of the relative bond strength showed that the addition of nanosilica affects the bond properties of both PCC and LCC. This result was confirmed via microstructural analysis of the macro PP fiber surface after the bond tests, which revealed an increase in scratches due to frictional forces and fiber tearing.
\end{abstract}

\section{Introduction}

Recently, a wide variety of high-performance and highdurability cementitious composites have been developed by improving structural functionality through the use of admixture materials such as nanomaterials [1-4]. Nanomaterials are currently attracting intense attention for their broad applicability to cementitious composites. Nanomaterials can produce tougher interfaces between aggregates and cement particles [5-8]. Such properties are advantageous for improving mechanical properties and long-term durability in cementitious composites [1-8]. Despite these advantages, introducing nanomaterials may increase the brittleness of composites; improved strength can lead to more cracking, especially if the particle size of the admixture is much smaller than that of the cement [1-4]. To resolve this problem, reinforcing fibers can be added [2, 9-15].

The ductile fracture of reinforcing fibers results from controlling the generation and growth of cracks in cementitious composites $[9,10,12-15]$. The degree of increase in energy-absorbing capacity attributable to fiber reinforcement of cementitious composites is determined by the bonding mechanism between the fibers and the cementitious composites, including fiber bridging, fiber debonding, fiber pullout, and fiber fracture when cracks occur [9, 12-15]. Bond characteristics are influenced by a variety of factors, such as the morphological shape and length of the reinforcing fiber, the surface properties, the interface between the cement composite and the reinforcing fiber, and the strength of the cement composite [9, 10,12-15].

Nanomaterials consist of very small particles. As the material fineness increases, the increase in surface area leads to an increase in moisture absorption, which decreases the workability of the material [1-4]. More water can be added to ensure sufficient workability, but adding water also increases the risk of crack formation during drying. Mechanical properties, such as strength and long-term durability, may also be negatively affected by the addition of water. Therefore, in general, it is important to increase the workability without increasing the unit water content. Latex polymer is 
TABle 1: Properties of latex polymer.

\begin{tabular}{lccccccc}
\hline $\begin{array}{l}\text { Solids } \\
\text { content (\%) }\end{array}$ & $\begin{array}{c}\text { Styrene } \\
\text { content (\%) }\end{array}$ & $\begin{array}{c}\text { Butadiene } \\
\text { content }(\%)\end{array}$ & $\mathrm{pH}$ & $\begin{array}{c}\text { Density } \\
\left(\mathrm{g} / \mathrm{mm}^{3}\right)\end{array}$ & $\begin{array}{c}\text { Surface tension } \\
(\text { dyne/cm })\end{array}$ & $\begin{array}{c}\text { Particle } \\
\text { size }(\mathrm{A})\end{array}$ & $\begin{array}{c}\text { Viscosity } \\
(\mathrm{cps})\end{array}$ \\
\hline 49 & $34 \pm 1.5$ & $66 \pm 1.5$ & 11.0 & 1.02 & 30.57 & 1700 & 42 \\
\hline
\end{tabular}

TABLE 2: Physical properties of cement.

\begin{tabular}{lccccccc}
\hline \multirow{2}{*}{ Surface area $\left(\mathrm{cm}^{2} / \mathrm{g}\right)$} & \multirow{2}{*}{ Density $\left(\mathrm{g} / \mathrm{mm}^{3}\right)$} & \multirow{2}{*}{ Stability $(\%)$} & \multicolumn{2}{c}{ Setting time } & \multicolumn{3}{c}{ Compressive strength $(\mathrm{MPa})$} \\
& & & Initial $(\mathrm{min})$ & Final $(\mathrm{min})$ & 3 days & 7 days & 28 days \\
\hline 3,200 & 3.15 & 0.02 & 220 & 400 & 20 & 30 & 38 \\
\hline
\end{tabular}

a semitransparent, milky liquid containing organic polymer colloidal microparticles $(0.5-5.0 \mu \mathrm{m}$ diameter) [16-19]. The particles, coated by surfactant, are dispersed in the solute, and the surfactant enables the formation of single-polymer cells via chain polymerization of the monomers. The surfactant delays solidification, stabilizes the particles, and increases the workability at a low water/cement ratio, while the latex polymer particles form a film during hydration [16-24]. Therefore, latex polymer may be used to resolve the problem of decreased workability of nanocementitious composites. The decrease in the amount of water used to secure the workability of nanocementitious composites can improve their mechanical properties and durability. In particular, in fiber-reinforced cementitious composites, the bonding performance of the reinforcing fibers can be improved by strengthening the interface between the fibers and cementitious composite.

This study evaluated the bond properties of macro polypropylene (macro PP) fibers in plain cementitious composites (PCCs) and styrene butadiene latex polymer cementitious composites (LCCs) containing varying amounts of nanosilica. Styrene butadiene latex polymer (latex polymer) replaced some (15 wt\%) of the binder, and $0-10 \mathrm{wt} \%$ of the binder was replaced with nanosilica.

\section{Experimental Procedure}

2.1. Materials. Latex polymer was obtained from Jungang Polytech, Korea. Table 1 lists its properties. Tables 2 and 3 list the properties of ASTM Type 1 cement and nanosilica, respectively. Macro PP fiber is a hydrophobic material widely used for cementitious composites. The fibers used in this study were straight, smooth monofilaments made of noncorrosive PP. Table 4 lists their properties.

2.2. Mix Proportions and Mixing Procedure. Table 5 lists the mix proportions of nanosilica used in this study to evaluate the bond properties between LCCs and macro PP fibers. The nanosilica contents ranged from 0 to $10 \%$ of the binder weight; latex polymer was used at $15 \%$ of the binder weight, and the water-to-binder ratio was 0.47 . The latex polymer used in this study was dispersion of $49 \mathrm{wt} \%$ solid polymer particles with the balance as water and surfactants. The "total latex polymer addition" noted in Table 5 refers to the amount of latex polymer used, that is, the combined solid and liquid contents. Latex polymer solid polymer particles were added at
TABle 3: Properties of nanosilica.

\begin{tabular}{lcc}
\hline Mean diameter $(\mathrm{nm})$ & Surface area $\left(\mathrm{cm}^{2} / \mathrm{g}\right)$ & $\mathrm{SiO}_{2}(\%)$ \\
\hline 10 & $5,000,000$ & $>99.8$ \\
\hline
\end{tabular}

TABle 4: Properties of macro polypropylene fiber.

\begin{tabular}{lc}
\hline Property & Polypropylene fiber \\
\hline Elastic modulus $(\mathrm{GPa})$ & 4.7 \\
Density $\left(\mathrm{g} / \mathrm{mm}^{3}\right)$ & 0.91 \\
Fiber length $(\mathrm{mm})$ & 30 \\
Fiber diameter $(\mathrm{mm})$ & 1 \\
Tensile strength $(\mathrm{MPa})$ & 470 \\
Surface & Hydrophobic \\
\hline
\end{tabular}

a weight ratio of latex polymer to binder of $15 \%$ (i.e., $90.9 \mathrm{~kg}=$ $606 \mathrm{~kg} \times 15 / 100(\%))$. The amount of water contained was $94.61 \mathrm{~kg} / \mathrm{m}^{3}$, and the added mixing water was $190.39 \mathrm{~kg} / \mathrm{m}^{3}$. However, the total amount of water was maintained at a constant level of $285 \mathrm{~kg} / \mathrm{m}^{3}$, and the water/binder ratio for the entire mixing process was maintained at a constant level of 0.47 . For the process of material mixing, cement, nanomaterials, and fine aggregates were added and dry-blended with a mixer for 30 minutes. Generally, mixing water was added over a period of 2 minutes and 30 seconds. Since the decrease of fluidity caused by the addition of nanomaterials makes thorough mixing difficult, an extra 5-minute blending time was used after adding all of the materials, to ensure sufficient blending of the mixture.

2.3. Slump Test. The slump test was carried out according to the ASTM C 143 standard to investigate how the added nanosilica affected the workability of the composite. Typically, when coarse aggregates are not used, the standard test method for flow of hydraulic cement mortar, ASTM C 143, is applied to measure composite workability. However, because latex polymer was used in this study, ASTM C 1437 could not be applied; the flowability was too high if nanosilica was not used. Therefore, the slump test was conducted according to ASTM C 143 instead.

2.4. Flexural Test. Flexural tests were conducted in accordance with the KS L ISO 679 standard [25]. Test mortar prism specimens measuring $40 \times 40 \times 160 \mathrm{~mm}$ were cured in water 
TABle 5: Mix proportions.

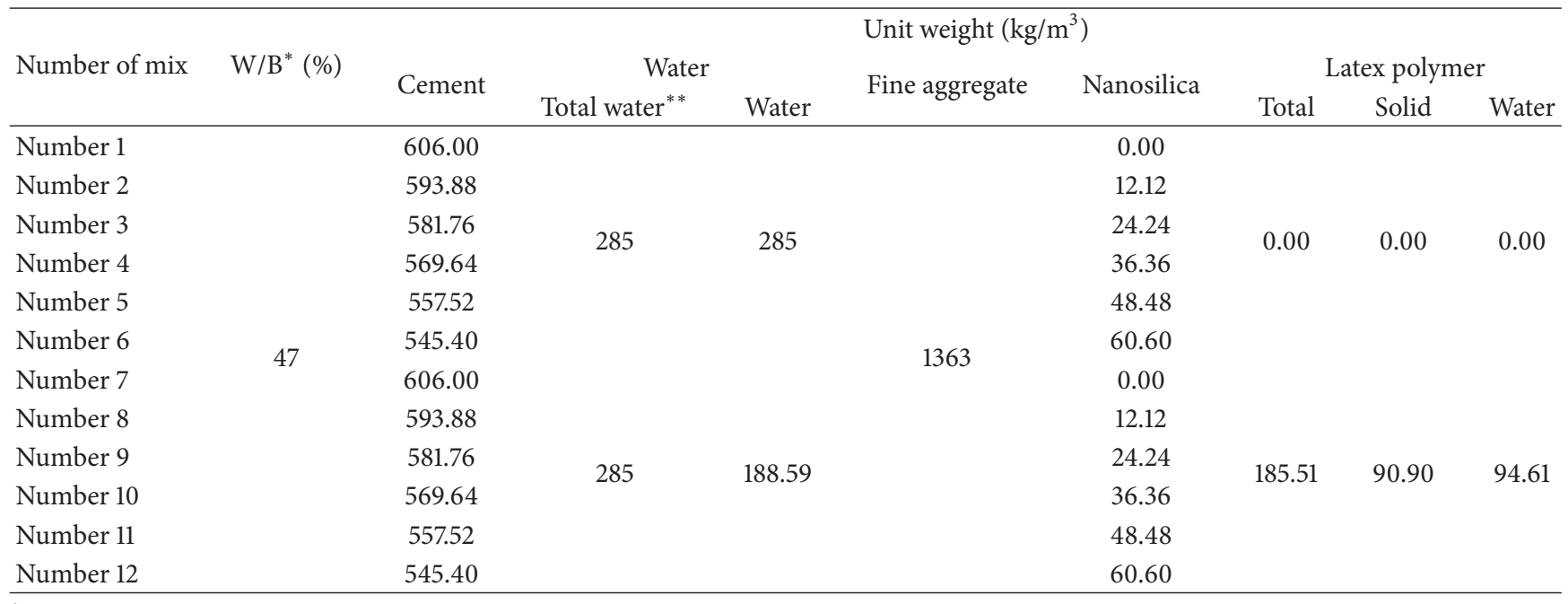

* Total water/(biner $=$ cement + nanosilica $)$.

** Water + water from the latex polymer.

at $23 \pm 2^{\circ} \mathrm{C}$. Each test was performed on six specimens that had been cured for 28 days. However, when nanosilica was added, it became difficult to cast and compact the test specimens due to increased viscosity and reduced workability. Thus, the mixing time was increased to 5 minutes after all materials were added, and compaction was carried out using vibrating table and rods. Each test was performed on six specimens that had been cured for 28 days.

2.5. Bond Test. Bond tests were conducted in accordance with the Japan Concrete Institute (JCI) SF-8 standard for fiber-reinforced concrete [26]. Bond tests were performed using a $50 \mathrm{kN}$ universal testing machine at a displacement rate of $0.5 \mathrm{~mm} / \mathrm{min}$ in the displacement-controlled mode. Figure 1 presents a schematic diagram of the preparation of specimens.

Tests were based on the assumption that the bond strength was distributed equally over the embedded length of the macroscale synthetic fiber. Therefore, (1) is not representative of the local bond stresses that occur over differing bond lengths. The pullout strength of the macroscale synthetic fiber was calculated according to $[9,20-22]$

$$
\tau_{\max }=\frac{P_{\max }}{\pi D L}
$$

where $\tau_{\max }$ is the maximum pullout strength, $P_{\max }$ is the maximum pullout load, $D$ is the fiber diameter, and $L$ is the embedded fiber length.

Interface toughness is critical for enhancing the ductility of reinforcing fibers in cementitious composites. This property is usually defined as the mechanical energy consumed during fiber pullout and can be determined by integrating the area under the pullout curve. The displacement required to measure the interface toughness in the JCI SF 8 standard is $2.5 \mathrm{~mm}$. The results of the pullout performance tests are presented as the mean values for six specimens.

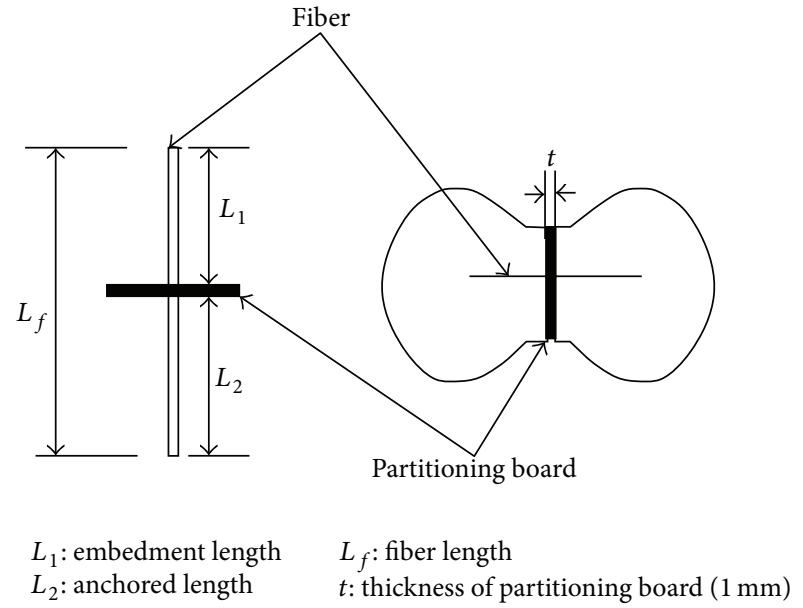

FIgURE 1: Arrangement of the partitioning board and fiber and setting in the mold.

2.6. Microstructure Analysis. To evaluate how the addition of nanosilica and latex polymer affected the behavior of the adhesion interface between the macro PP fiber and the cement matrix, the pullout resistance mechanism was analyzed using scanning electron microscopy (SEM) analyses of the macro PP fiber surface after the pullout test. After completing the pullout test, SEM images (100x magnification) of the fiber pulled out of the cement matrix were obtained, and the influence of the added nanosilica and latex polymer on the friction resistance during the fiber pullout was analyzed based on the scratches observed on the fiber surface.

\section{Results and Discussion}

3.1. Slump. Figure 2 presents the results of slump testing of PCCs and LCCs as a function of added nanosilica. The slump value for PCCs decreased below $50 \mathrm{~mm}$ when more than $2 \mathrm{wt} \%$ of nanosilica was added, and was $0 \mathrm{~mm}$ when $4 \mathrm{wt} \%$ 


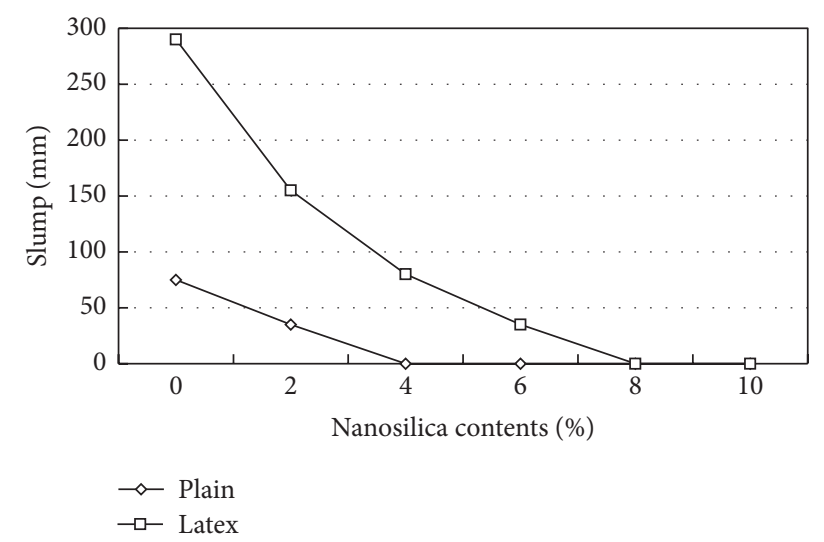

FIGURE 2: Slump value of PCC and LCC with nanosilica contents.

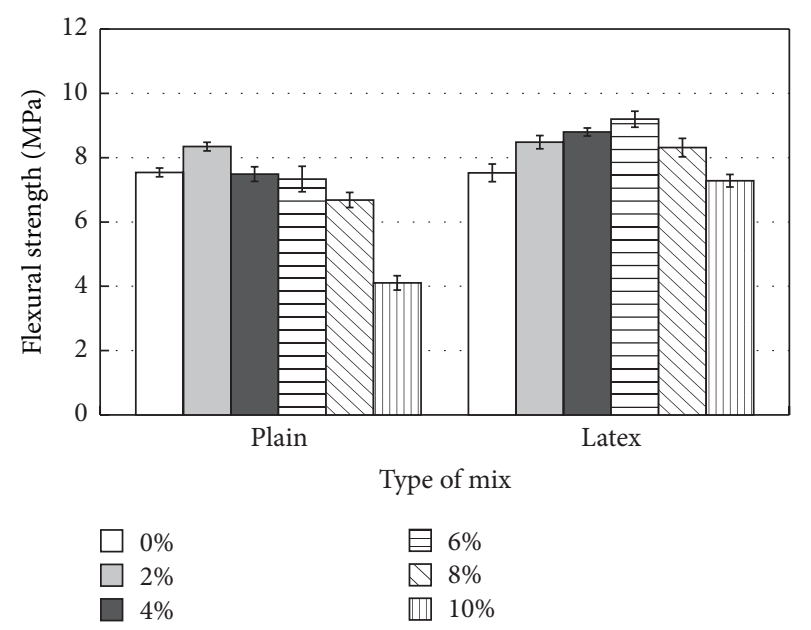

FIgURE 3: Flexural strength of PCC and LCC with nanosilica contents.

was used. The slump value for LCCs decreased strongly with increasing nanosilica content and was $0 \mathrm{~mm}$ at weightings of $8 \mathrm{wt} \%$ or more. Therefore, latex polymer is effective at increasing the workability of cementitious composites [1624]. The latex polymer particles, coated with surfactant, are dispersed in the solute, and the surfactant enables the formation of single-polymer cells via chain polymerization of the monomers. The surfactant delays solidification, stabilizes the particles, and increases the workability at a low water/cement ratio [16-24].

3.2. Flexural Strength. Figure 3 presents the results for flexural strength testing of PCCs and LCCs containing various nanosilica contents. The flexural strength of LCCs increased in the presence of nanosilica at contents up to $6 \mathrm{wt} \%$ and decreased at contents of $8 \mathrm{wt} \%$ or more. However, in the case of PCCs, flexural strength increased at contents up to $2 \mathrm{wt} \%$ of nanosilica but decreased at levels greater than $4 \mathrm{wt} \%$. Initially, the nanosilica particles filled the voids in the cementitious composites [5-8], thereby increasing the flexural strength. However, as the addition rate increased, so did the specific surface area and absorption of water [1-4]. This increase in water absorption deteriorated the workability and hindered

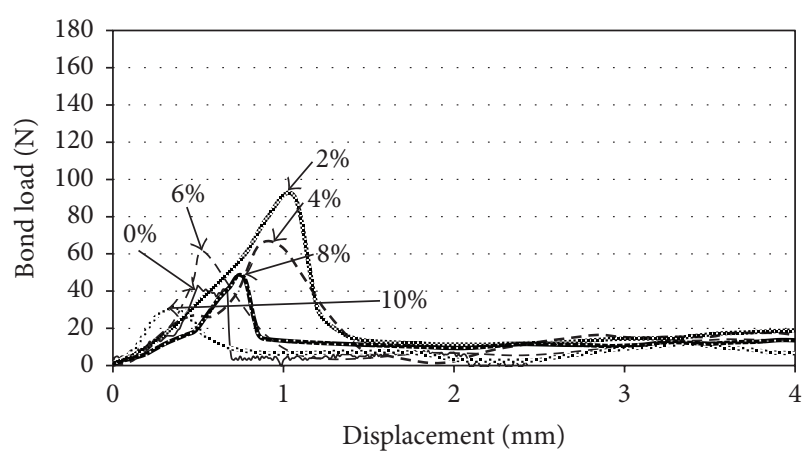

(a) PCC

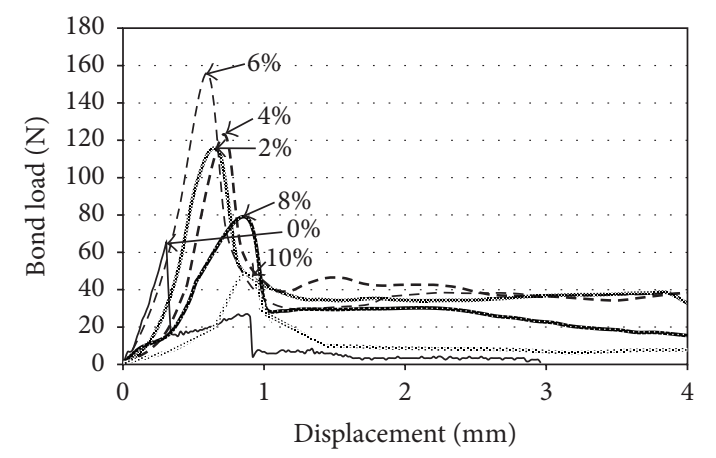

(b) LCC

FIgure 4: Pullout behavior of macro PP fiber in PCC and LCC with nanosilica contents.

material mixing, casting, and compacting of test specimens. Air voids formed in the test specimens and decreased the flexural strength. Latex polymer was effective at improving the workability of cementitious composites [16-24], so LCCs exhibited better workability at the same addition rate of nanosilica compared to PCCs. Additionally, latex polymer formed a film around the aggregate and improved flexural strength $[18,19,23]$.

3.3. Bond Behavior. Figure 4 presents the bond load versus displacement curves of the macro PP fiber at different nanosilica contents. The bonding behavior of the reinforcing fibers in LCCs and PCCs can be classified into precracked zones and debonded zones [9, 10, 13-15, 27]: the former exhibits linear elastic behavior, while the latter displays different behaviors depending on the frictional forces and the rate of crack growth at the interface between the reinforcing fibers and the cementitious composites $[9,10,13-15]$. In this study, linear elastic behavior was observed in the precracked zone, and pullout behavior was observed in the debonded zone after cracks occurred and the bond load was reduced. In the case of LCCs, the peak bond load in the precracked zone increased up to $6 \mathrm{wt} \%$ of nanosilica but decreased at levels greater than $8 \mathrm{wt} \%$. The behavior in the debonded zone exhibited a similar pattern: up to $6 \mathrm{wt} \%$ of nanosilica, the displacement at the same bond load increased, and the bond load at the same displacement increased. However, at nanosilica contents of $8 \mathrm{wt} \%$ or more, the displacement at the same bond load decreased, and the bond load at the same displacement decreased. For PCCs, the peak bond load in 


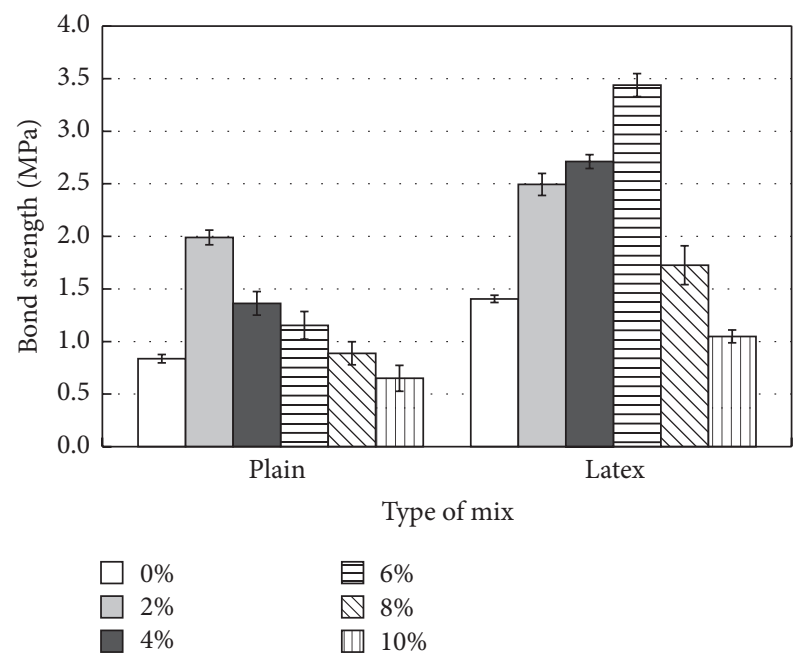

(a) Bond strength

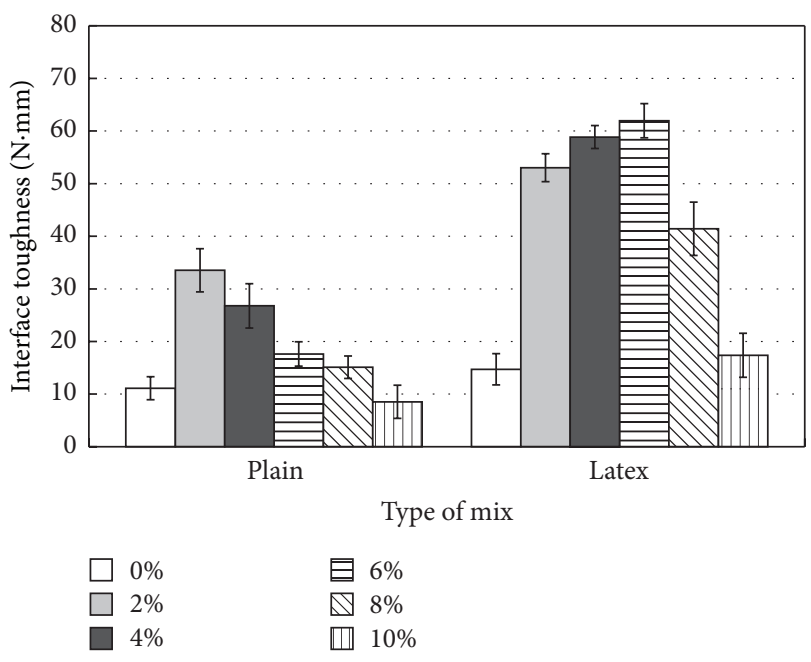

(b) Interface toughness

FIGURE 5: Bond strength and interface toughness of macro PP fiber in PCC and LCC with nanosilica contents.

the precracked zone increased up to $2 \mathrm{wt} \%$ of nanosilica but decreased at levels greater than $4 \mathrm{wt} \%$. The behavior in the debonded zone showed a similar tendency. This result can be attributed to two factors. First, given the much smaller particle size of the nanosilica compared to that of the cement, the nanosilica particles filled the voids at the interface of the macro PP fiber and the cementitious composites, thereby strengthening the interface so that the peak bond load increased. Second, increased frictional forces at the interface after the occurrence of cracks suppressed pullout of the macro PP fibers. However, the more nanosilica was added, the more mixing water was absorbed because of the increased specific surface area, which resulted in higher cement viscosity and decreased workability [1-4]. The higher viscosity hindered casting and compacting of the cementitious composites and tended to weaken the bonding between the cementitious composites and macro PP fibers. By contrast, the superior workability of LCCs enabled easier casting and compacting of test specimens and improved bonding in LCCs compared to PCCs.

3.4. Bond Strength and Interface Toughness. Figure 5 shows the bond strengths and interface toughness values for different nanosilica contents. For LCCs, the bond strengths in the composites at nanosilica contents from 0 to $10 \mathrm{wt} \%$, in $2 \mathrm{wt} \%$ increments, were $1.41,2.49,2.71,3.43,1.72$, and $1.04 \mathrm{MPa}$, respectively. The bond strength increased with nanosilica contents up to $6 \mathrm{wt} \%$ and then decreased for contents greater than $8 \mathrm{wt} \%$. In the case of PCCs, at the same nanosilica contents in $2 \mathrm{wt} \%$ increments from 0 to $10 \mathrm{wt} \%$, the values were $0.84,1.99,1.36,1.15,0.88$, and $0.65 \mathrm{MPa}$, respectively. In this case, the bond strength increased for nanosilica contents of up to $2 \mathrm{wt} \%$ and then decreased for contents greater than $4 \mathrm{wt} \%$. For LCCs, the interface toughness values for nanosilica contents from 0 to $10 \mathrm{wt} \%$, in $2 \mathrm{wt} \%$ increments, were $14.72,53.03,58.56,61.96,41.42$, and $17.38 \mathrm{~N}-\mathrm{mm}$, respectively. As with bond behavior and bond strength, the interface toughness of the LCCs increased for nanosilica contents of up to $6 \mathrm{wt} \%$ and then decreased when the content was $8 \mathrm{wt} \%$ or greater. For PCCs, the corresponding interface toughness values were 11.12, 33.53, $26.27,17.63,15.11$, and $8.54 \mathrm{~N}$-mm for nanosilica contents in $2 \mathrm{wt} \%$ increments from 0 to $10 \mathrm{wt} \%$, respectively. Thus, interface toughness in PCCs increased when the nanosilica content increased from 0 to $2 \mathrm{wt} \%$ and then decreased when the content was $4 \mathrm{wt} \%$ or more. These trends can be attributed to decreasing cement workability caused by greater absorption of mixing water with increasing nanosilica contents. This decreased workability hindered compaction of test specimens and introduced voids at the bond interface between the macro PP fiber and the cementitious composites, thereby resulting in decreased bond strength and interface toughness. However, the addition of latex polymer increased the workability of cementitious composites and facilitated compaction of test specimens [16-24]. The latex polymer also formed a film that improved adhesion between materials and improved the bond strength and toughness at the same nanosilica content compared with PCCs.

3.5. Relationship between Flexural Strength and Bond Performance. Figure 6 presents the correlation between flexural strength and bond performance at different nanosilica contents. The flexural strength, bond strength, and interface toughness behaviors at different nanosilica contents were quite similar. For LCCs, the flexural strength, bond strength, and interface toughness increased with increasing nanosilica content up to $6 \mathrm{wt} \%$ and then decreased at contents of $8 \mathrm{wt} \%$ or more. For PCCs, the flexural strength, bond strength, and interface toughness increased with increasing nanosilica content up to $2 \mathrm{wt} \%$ but decreased at nanosilica contents of $4 \mathrm{wt} \%$ or more. These results indicate that strength and bond characteristics are closely related.

3.6. Relative Bond Strength. The relative bond properties were analyzed to evaluate the effects of nanosilica on bond 


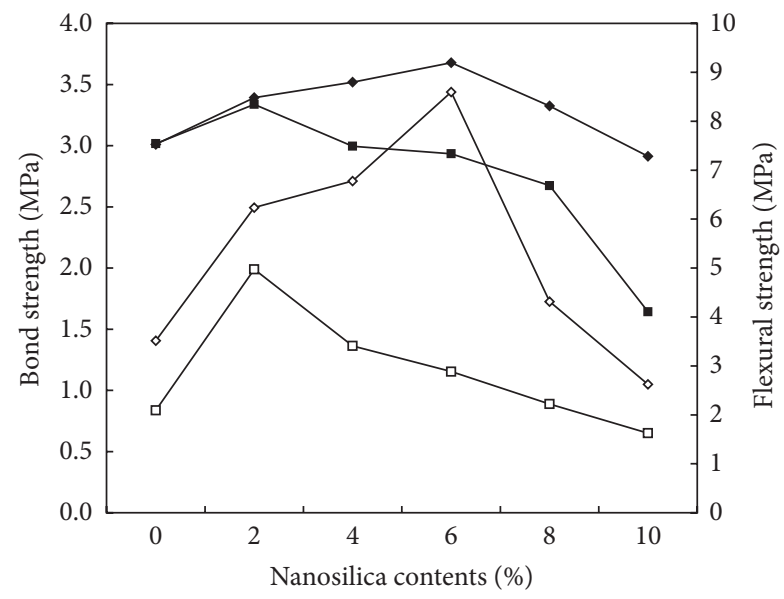

$\rightarrow$ Plain-bond strength $\quad \longrightarrow$ Latex-bond strength
$\rightarrow$ Plain-flexural strength $\rightarrow$ Latex-flexural strength

(a) Bond strength

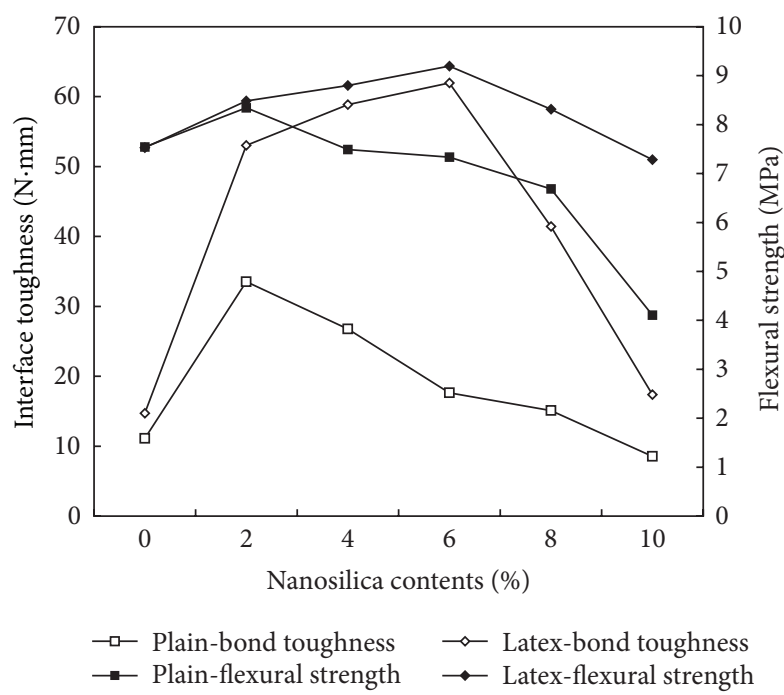

(b) Interface toughness

FIGURE 6: Relationship between flexural strength and bond performance.

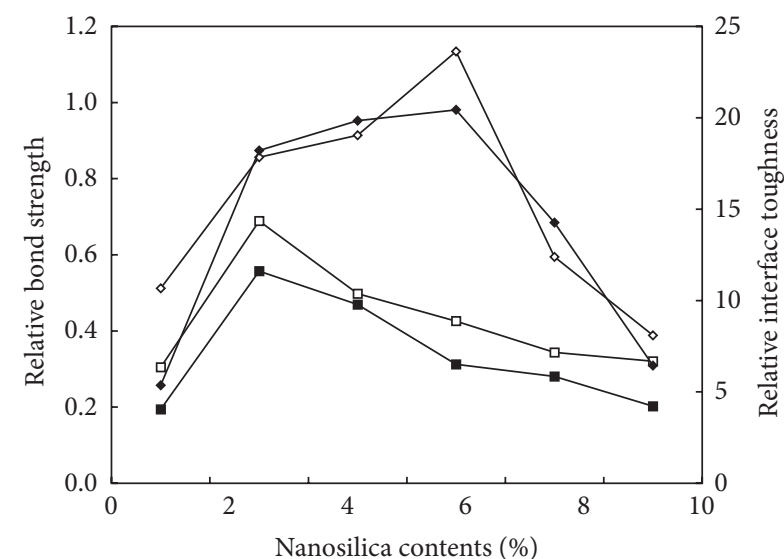

$\begin{array}{ll}\rightarrow-\text { Plain-relative bond strength } & \rightarrow \text { Latex-relative bond strength } \\ \rightarrow \text { Plain-interface toughness } & \rightarrow \text { Latex-interface toughness }\end{array}$

FIGURE 7: Relative bond strength of macro PP fiber in PCC and LCC with nanosilica contents.

properties. The relative bond properties were determined using [27]

$$
R_{b}=\frac{\tau_{\max }}{\sqrt[2]{f_{T}}}
$$

where $R_{b}$ is the relative bond strength, $\tau_{\max }$ is the maximum bond strength, and $f_{T}$ is the flexural strength.

Figure 7 presents the results for relative bond strength and relative interface toughness. Both bond strength and interface toughness in the composites were influenced by the nanosilica content, regardless of flexural strength. In the case of PCCs, the relative bond strengths were 0.30, $0.69,0.49,0.42,0.34$, and 0.32 for nanosilica contents of 0 , $2,4,6,8$, and $10 \mathrm{wt} \%$, respectively. In the case of LCCs, the relative bond strengths were $0.51,0.85,0.91,1.13,0.59$, and 0.39 , respectively, for the same nanosilica contents. For LCCs, the relative interface toughness values were 5.37, 18.21, $19.84,20.43,14.27$, and 6.44 for nanosilica contents of 0,2 , $4,6,8$, and $10 \mathrm{wt} \%$, respectively. For PCCs, the interface toughness values at the same nanosilica contents were 4.05 , $11.61,9.78,6.51,5.84$, and 4.21 , respectively. The relative bond strength and interface toughness exhibited the same tendency as bond strength with increasing nanosilica content. Thus, the nanosilica content significantly influenced the bond strength and interface toughness of macro PP fiber in PCCs and LCCs.

3.7. Microstructural Analysis. After the bond tests, the surface morphology of the macro PP fiber was studied using SEM. Figure 8 shows images of the fiber surface after the bond tests for PCCs to which nanosilica was added. Figures $8(a)-8(f)$ correspond to fibers after bond tests at nanosilica contents of $0,2,4,6,8$, and $10 \mathrm{wt} \%$, respectively. Figure 8(a) shows the scratching and tearing of fibers on the surface at both ends of the fibers. In Figure 8(b), the scratching and tearing increased, and the tearing extended to the central part of the fibers; a considerable amount of nanosilica powder is seen on the surface. Figure 8(c) shows that the surface of the fiber caved in as a result of the tearing, due to the friction force on the fibers. In Figure 8(d), nanosilica powder is seen on the surface along with tearing of the fiber. In Figure 8(e), there is less tearing of the surface and some nanosilica powder. In Figure 8(f), slight tearing of the surface and only a small amount of nanosilica powder on the surface were evident.

Figure 9 presents SEM images of the fiber surface after bond tests of LCCs to which nanosilica was added. Figure 9(a) shows evidence of scratching on the surface. Figure 9(b) shows the remaining nanosilica powder and tearing of the surface. Figure 9(c) shows tearing of the fibers, although the tearing appeared to be partial. Figure 9 (d) shows tearing of the fiber and surface scratching over a significant portion of the fiber surface. Figure 9(e) shows that although 


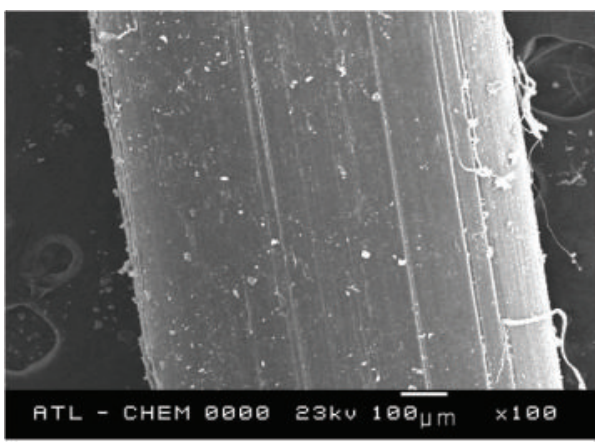

(a) $0 \%$

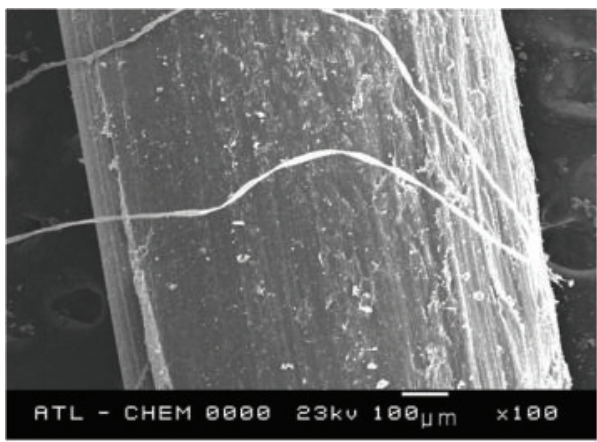

(c) $4 \%$

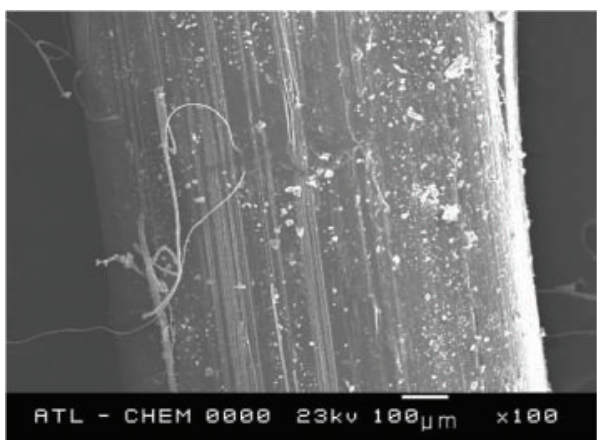

(e) $8 \%$

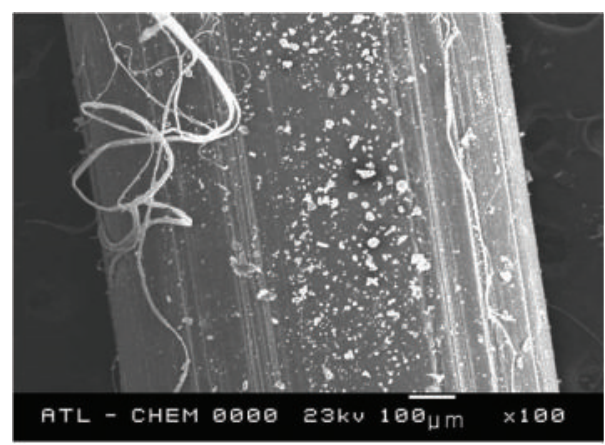

(b) $2 \%$

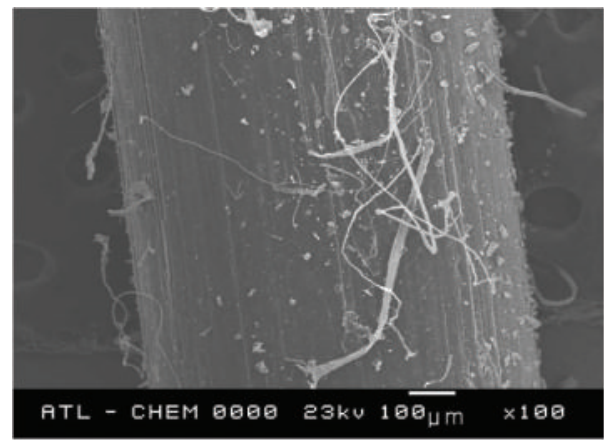

(d) $6 \%$

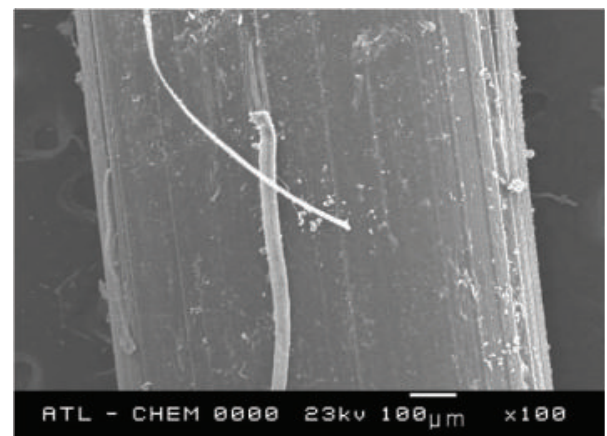

(f) $10 \%$

FIGURE 8: SEM investigation of macro PP fiber surface in PCC with nanosilica contents.

tearing and scratching appeared over the entire fiber surface, this phenomenon tended to decrease after $6 \%$ nanosilica addition. Figure 9(f) shows the tearing and scratching of the fiber over a portion of the fiber surface.

Scratching of the fiber surface and tearing of the fiber occurred for PCCs and LCCs during pullout of macro PP fibers. Pullout resistance of the fibers improved as frictional forces increased, and greater pullout resistance improved interface toughness. Scratches generated by frictional forces at the fiber surface caused fiber tearing and exhibited a trend similar to that observed for interface toughness.

\section{Conclusions}

This study evaluated the bond behavior of macro PP fiber in PCCs and LCCs at different nanosilica contents. Dog-bone specimens were used for the bond tests according to the JCI
SF- 8 standard. The microstructures of the fiber surfaces after the bond tests were studied to investigate the bonding mechanisms between the fibers and the cementitious composites containing nanosilica. The results are summarized as follows:

(i) Slump tests indicated that, for both PCCs and LCCs, at higher nanosilica contents, the viscosity increased and the slump value decreased. However, at the same nanosilica content, the slump value of LCCs was greater than that of PCCs, because latex polymer increased the workability of cementitious composites.

(ii) Bond strength and interface toughness tests revealed that both properties increased for nanosilica contents of up to $2 \mathrm{wt} \%$ but then decreased at contents greater than $4 \mathrm{wt} \%$. Bond strength and interface toughness of macro PP fiber and LCCs increased at nanosilica contents up to $6 \mathrm{wt} \%$. However, the bond strength and interface toughness decreased for contents of 


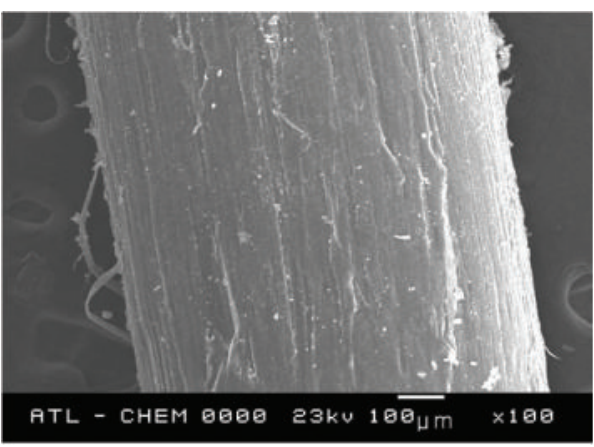

(a) $0 \%$

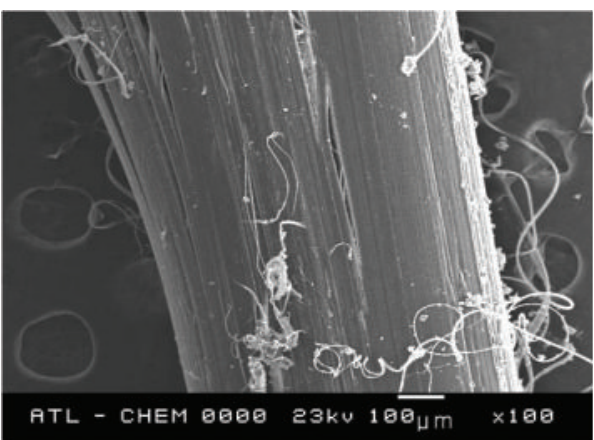

(c) $4 \%$

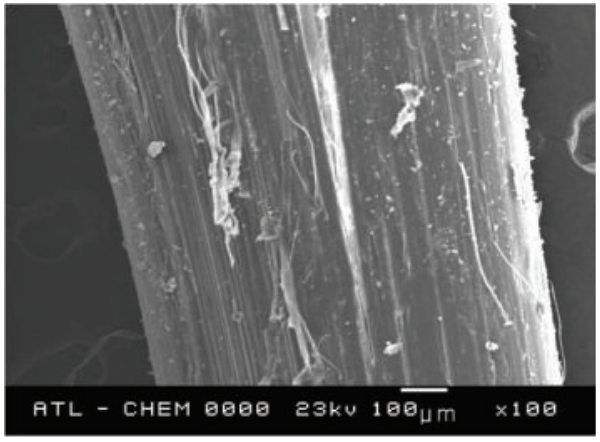

(e) $8 \%$

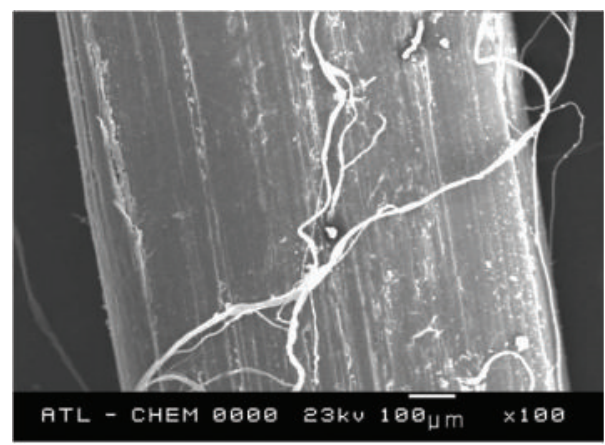

(b) $2 \%$

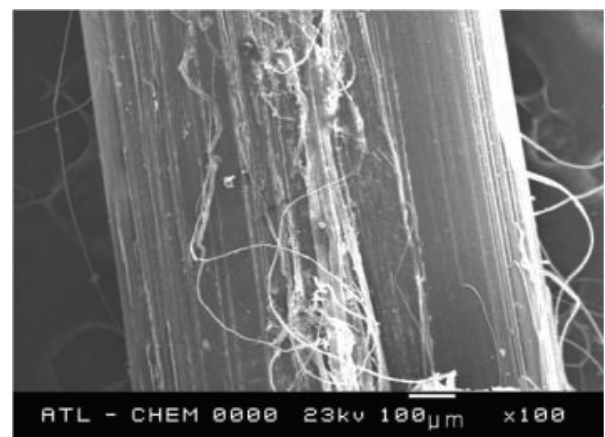

(d) $6 \%$

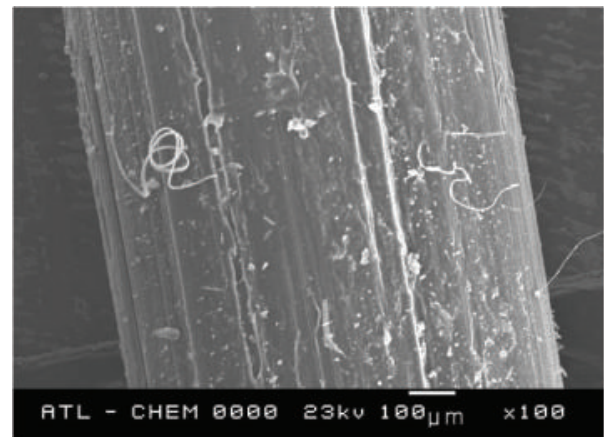

(f) $10 \%$

FIGURE 9: SEM investigation of macro PP fiber surface in LCC with nanosilica contents.

$8 \mathrm{wt} \%$ and greater. Latex polymer also increased the adhesion between materials, so the bond strength and interface toughness were relatively better in LCCs than in PCCs.

(iii) Relative bond performance was also analyzed to evaluate how the addition of nanosilica to the composites influenced the bond performance between macro PP fiber and cementitious composites. Nanosilica significantly affected the bond performance between the macro PP fiber and the cementitious composites. The addition of latex polymer increased the relative bond strength between the cementitious composites and the macro PP fiber at a given nanosilica content.

(iv) Post-bond-test microstructural analyses of the fiber surfaces confirmed the results of the bond performance tests. The severity of scratching and fiber tearing of the macro PP fiber surface due to frictional forces followed the same trend as that observed for bond strength and interface toughness. Nanosilica particles filled the interface voids between the macro PP fiber and the cementitious composites and affected the bonding mechanism.

\section{Conflict of Interests}

The authors declare that there is no conflict of interests regarding the publication of this paper.

\section{Acknowledgment}

This work was supported by the research grant of the Kongju National University in 2014. 


\section{References}

[1] L. Senff, J. A. Labrincha, V. M. Ferreira, D. Hotza, and W. L. Repette, "Effect of nano-silica on rheology and fresh properties of cement pastes and mortars," Construction and Building Materials, vol. 23, no. 7, pp. 2487-2491, 2009.

[2] M. Ali, X. Li, and N. Chouw, "Experimental investigations on bond strength between coconut fibre and concrete," Materials and Design, vol. 44, pp. 596-605, 2013.

[3] M.-H. Zhang and H. Li, "Pore structure and chloride permeability of concrete containing nano-particles for pavement," Construction and Building Materials, vol. 25, no. 2, pp. 608-616, 2011.

[4] M.-H. Zhang, J. Islam, and S. Peethamparan, "Use of nano-silica to increase early strength and reduce setting time of concretes with high volumes of slag," Cement and Concrete Composites, vol. 34, no. 5, pp. 650-662, 2012.

[5] T. Ji, "Preliminary study on the water permeability and microstructure of concrete incorporating nano-SiO ${ }_{2}$," Cement and Concrete Research, vol. 35, no. 10, pp. 1943-1947, 2005.

[6] M. Amin and K. Abu El-Hassan, "Effect of using different types of nano materials on mechanical properties of high strength concrete," Construction and Building Materials, vol. 80, pp. 116124, 2015.

[7] J. Nirmala and G. Dhanalakshmi, "Influence of nano materials in the distressed retaining structure for crack filling," Construction and Building Materials, vol. 88, pp. 225-231, 2015.

[8] H. Li, H.-G. Xiao, J. Yuan, and J. Ou, "Microstructure of cement mortar with nano-particles," Composites Part B: Engineering, vol. 35, no. 2, pp. 185-189, 2004.

[9] A. Bentur and S. Mindess, Fibre Reinforced Cementitious Composites, Elsevier Applied Science, London, UK, 1997.

[10] Y.-W. Chan and S.-H. Chu, "Effect of silica fume on steel fiber bond characteristics in reactive powder concrete," Cement and Concrete Research, vol. 34, no. 7, pp. 1167-1172, 2004.

[11] F. D. A. Silva, B. Mobasher, C. Soranakom, and R. D. T. Filho, "Effect of fiber shape and morphology on interfacial bond and cracking behaviors of sisal fiber cement based composites," Cement and Concrete Composites, vol. 33, no. 8, pp. 814-823, 2011.

[12] B. Mobasher and C. Y. Li, "Effect of interfacial properties on the crack propagation in cementitious composites," Advanced Cement Based Materials, vol. 4, no. 3-4, pp. 93-105, 1996.

[13] A. E. Naaman and H. Najm, "Bond-slip mechanisms of steel fibers in concrete," ACI Materials Journal, vol. 88, no. 2, pp. 135$145,1991$.

[14] M. J. Shannag, R. Brincker, and W. Hansen, "Pullout behavior of steel fibers from cement-based composites," Cement and Concrete Research, vol. 27, no. 6, pp. 925-936, 1997.

[15] S. Singh, A. Shukla, and R. Brown, "Pullout behavior of polypropylene fibers from cementitious matrix," Cement and Concrete Research, vol. 34, no. 10, pp. 1919-1925, 2004.

[16] B. Muhammad, M. Ismail, M. A. R. Bhutta, and Z. Abdul-Majid, "Influence of non-hydrocarbon substances on the compressive strength of natural rubber latex-modified concrete," Construction and Building Materials, vol. 27, no. 1, pp. 241-246, 2012.

[17] C. T. Sumathy, M. Dharakumar, M. Saroja Devi, and S. Saccubai, "Modification of cement mortars by polymer latex," Journal of Applied Polymer Science, vol. 63, no. 10, pp. 1251-1257, 1997.

[18] M. Sprinkel, "Very-early-strength latex-modified concrete over-lays," Tech. Rep. TAT99-TAR3, Virginia Transportation Research Council, Charlottesville, Va, USA, 1998.
[19] D.-H. Kim and C.-G. Park, "Strength, permeability, and durability of hybrid fiber-reinforced concrete containing styrene butadiene latex," Journal of Applied Polymer Science, vol. 129, no. 3, pp. 1499-1505, 2013.

[20] J.-Y. Jung, C.-G. Park, and J.-S. Park, "Bond properties of structural polypropylene fiber in hybrid nonstructural polypropylene and structural polypropylene fiber-reinforced latexmodified cement-based composites," Journal of Applied Polymer Science, vol. 127, no. 2, pp. 1221-1227, 2013.

[21] J.-Y. Jung, J.-H. Lee, and C.-G. Park, "Effect of styrene-butadiene latex on the bond performance of macro synthetic fiber in micro jute/macro synthetic hybrid fiber-reinforced latex-modified cement-based composites," Journal of Applied Polymer Science, vol. 127, no. 5, pp. 3522-3529, 2013.

[22] C.-G. Park and J.-H. Lee, "Effect of styrene butadiene latex polymer contents on the bond properties of macro polypropylene fiber in polymer-modified cement-based composites," Journal of Applied Polymer Science, vol. 126, no. 2, pp. E330-E337, 2012.

[23] J.-P. Won, J.-H. Kim, S.-W. Lee, and C.-G. Park, "Durability of low-heat, ultra rapid-hardening, latex-modified polymer concrete," Progress in Rubber, Plastics and Recycling Technology, vol. 25, no. 2, pp. 91-102, 2009.

[24] C. T. Sumathy, M. Dharakumar, M. Saroja Devi, and S. Saccubai, "Modification of cement mortars by polymer latex," Journal of Applied Polymer Science, vol. 63, no. 10, pp. 1251-1257, 1997.

[25] Korea Standard Association, Korea Standard Testing Method L ISO 679, Testing Method for Strength of Hydraulic Cement Mortar, Korea Standard Association, Seoul, Republic of Korea, 2002.

[26] Committee on Fiber Reinforced Concrete JCI-SF8, Method of Testing for Bonds of Fibers, Japan Concrete Institute, Tokyo, Japan, 1984.

[27] J. Xiao and H. Falkner, "Bond behaviour between recycled aggregate concrete and steel rebars," Construction and Building Materials, vol. 21, no. 2, pp. 395-401, 2007. 

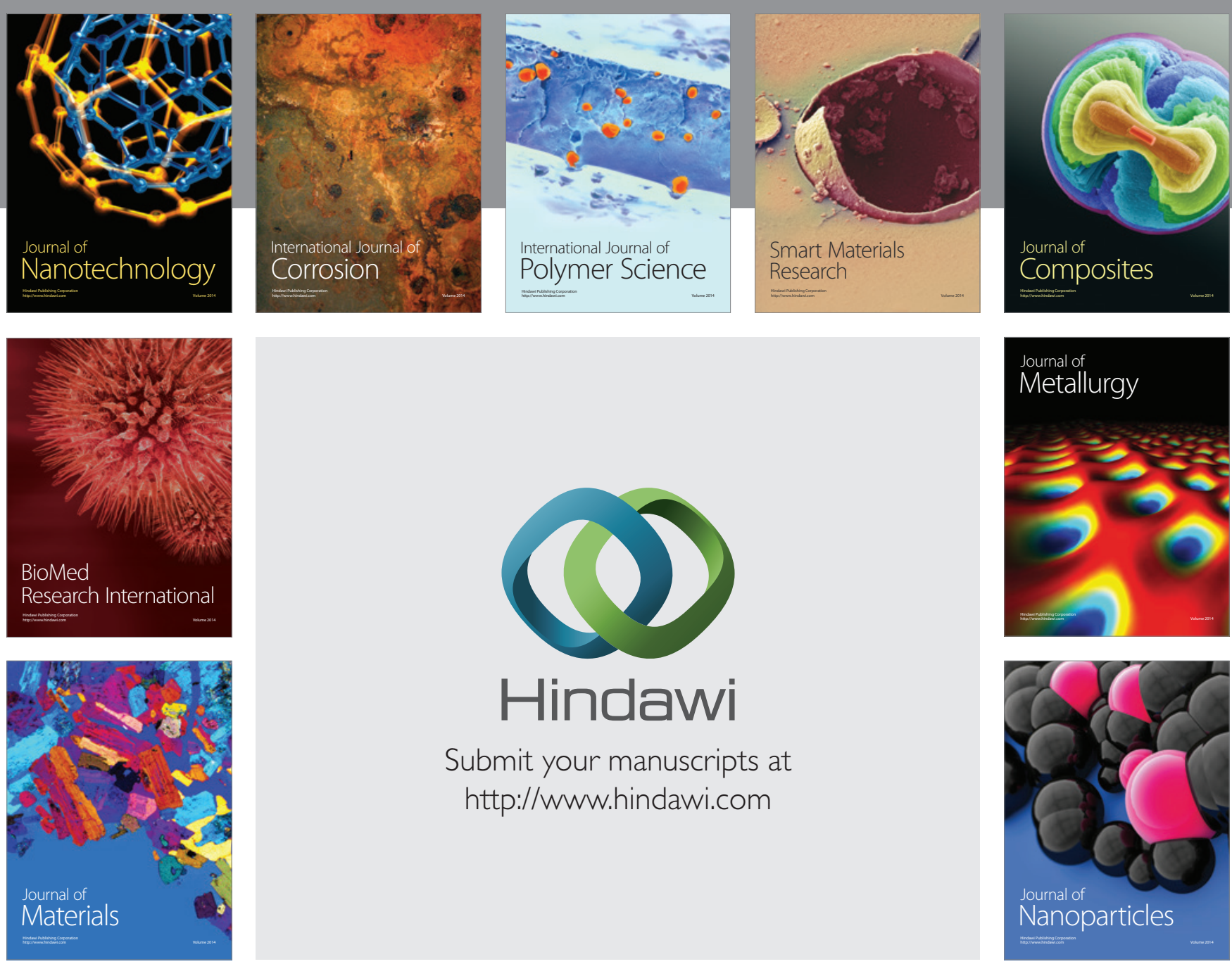

Submit your manuscripts at http://www.hindawi.com
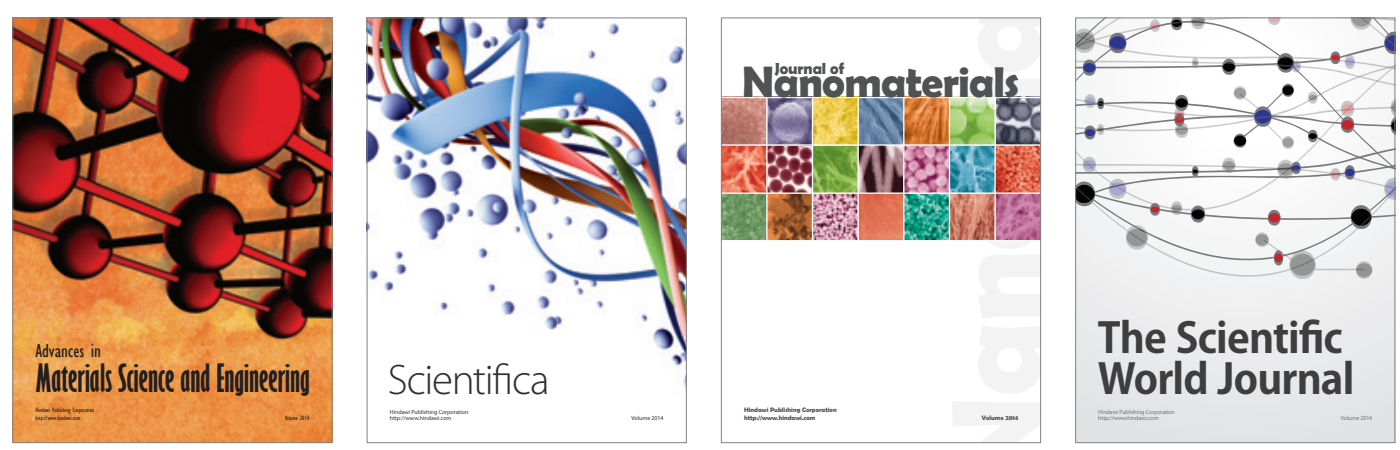

\section{The Scientific World Journal}
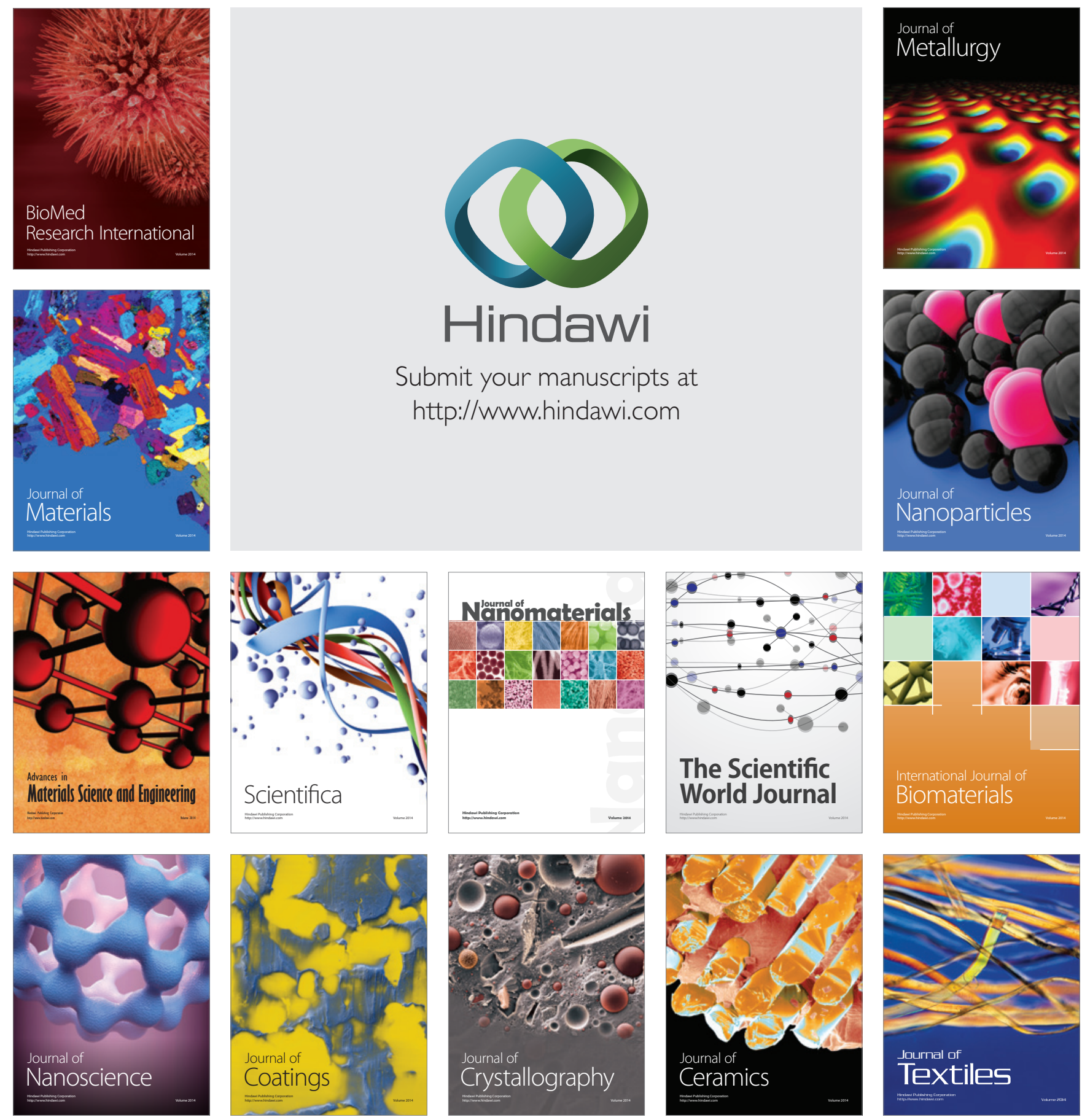